\title{
Off-pump, multiple arterial grafting with minimal aortic manipulation: Is it for everyone?
}

\section{No, but more patients should be having it!}

The field of surgical revascularization was revolutionized in the 1980s by proponents of the left internal thoracic artery (LITA) graft and by the survival benefit of the LITA-left anterior descending artery graft demonstrated by Loop and colleagues. ${ }^{1}$ Since then, even as medical therapy and percutaneous interventions have continued to advance, the vast majority of coronary artery bypass graft (CABG) operations performed in the Western world have remained unchanged: an on-pump procedure with a single internal thoracic artery (ITA) plus vein grafts. According to the Society of Thoracic Surgeons Adult Cardiac Surgery Database, in 2009 only $4.1 \%$ of isolated primary CABG cases in North America used a bilateral ITA (BITA) graft, and $5.5 \%$ used a radial artery graft. ${ }^{2}$

It is important to point out that CABG with single ITA plus vein grafts is still a good procedure and was used to demonstrate survival benefit over percutaneous coronary intervention using drug-eluting stents in the SYNTAX and FREEDOM trials. ${ }^{3,4}$ Nonetheless, over the past 3 decades, surgical scientists around the world have developed novel techniques in surgical coronary revascularization and rigorously tested the incremental benefits of these techniques. These efforts have resulted in a procedure performed by revascularization experts without cardiopulmonary bypass that lowers the risk of stroke and offers the benefit of long term patency of arterial revascularization, namely offpump, multiple arterial grafting with minimal aortic manipulation.

The first major advantage of this state-of-the-art approach to surgical coronary revascularization is the use of multiple or all-arterial grafts. There is no doubt that arterial grafts have greater long-term patency than vein grafts in most situations, and their use is associated with improved survival and reduced adverse cardiovascular events. Although most evidence favoring the use of multiple arterial grafts is for the use of both ITAs, a randomized trial also showed significant superior patency of the radial artery over vein grafts after 5 years of follow-up.

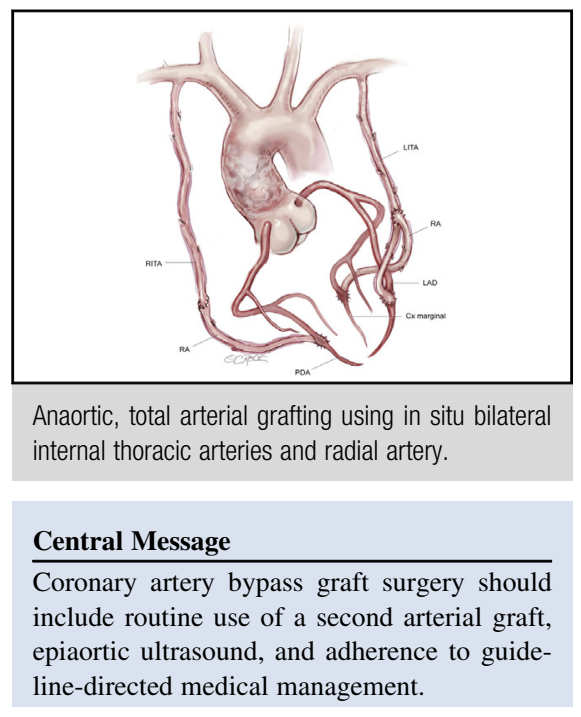

See Articles page 60 and page 1526 in the December issue.

See Editorial Commentary page 78.
To date, there has been one randomized trial (the Arterial Revascularization Trial) of single ITA grafts versus BITA grafts, whose primary outcome is 10-year survival and that will report in 2018. In this trial, analysis at an interim 1-year "safety" endpoint showed that the use of BITA did not increase mortality or myocardial infarction compared with a single ITA, but did lead to a small increase in the risk of sternal wound reconstruction (largely in patients with diabetes who were also obese). ${ }^{6}$ However, using large observational cohorts, Lytle and others have conclusively demonstrated that "two ITAs are better than one" in terms of survival. ${ }^{7,8}$ Subsequently, several systematic reviews have confirmed this observation and have noted that this benefit persists to at least 9 years of follow-up..$^{9-11}$ Most recently, the same survival benefit has been shown specifically in patients with diabetes. ${ }^{12}$

Total arterial revascularization is often accomplished with a combination of BITA and radial artery grafts, sometimes including the use of sequential, composite, and/or more complex "Y" or "K" grafting (Figure 1). BITA grafting is complicated by an increased risk of sternal wound infection, but this may be mitigated with a minimally traumatic skeletonized ITA harvest, especially 
when performed with a harmonic scalpel and particularly in patients with diabetes. ${ }^{12,13}$

The second major advantage is a reduced risk of perioperative stroke. In trials comparing percutaneous coronary intervention with surgical revascularization, including the SYNTAX and FREEDOM trials, stroke remained a limitation of surgery. ${ }^{3,4}$ Efforts aimed at stroke reduction include eliminating cardiopulmonary bypass and minimizing aortic manipulation. Routine epiaortic ultrasound is a fast and sensitive method for assessing the extent of plaque burden in the ascending aorta. ${ }^{14}$ Replacing the aortic side-biting (partial occlusion) clamp for proximal anastomoses during off-pump CABG with an alternative clampless facilitating devices is one way to reduce aortic manipulation. A completely "anaortic" operation with ITA inflow(s) and multiple arterial sequential and/or Y grafts eliminates aortic manipulation and has been shown to further reduce the risk of stroke to levels similar to those reported with multivessel percutaneous coronary intervention. ${ }^{15}$

It is self-evident that the state-of-the-art surgical revascularization outlined above adds several levels of complexity, including the difficulty of establishing exposure and stabilization to allow the surgeon to sew precise anastomoses on a beating heart using complex arterial grafting techniques while maintaining hemodynamic stability and minimizing coronary ischemia. Moreover, planning and executing total revascularization may be difficult when only limited arterial conduits are available. Atraumatic endoscopic harvesting of radial arteries requires expertise that is not yet widely disseminated among surgeons and surgical assistants.

Nonetheless, even if the state-of-the-art procedure is not practical for all surgeons (or all patients), all surgeons can adopt some changes to improve the clinical outcomes of CABG (Figure 2). In other words, the state of the art should not be considered a "set menu," but rather viewed as an "a la carte" opportunity to provide better care to CABG patients. Surgical coronary revascularization should be thoughtfully individualized for each patient by each operating team. In this spirit, some changes could be easily adopted by all coronary surgeons for almost all patients.

The first change that would make a profound improvement in long-term clinical outcomes for our patients with a minimal increase in complexity would be the adoption of a second arterial graft. This great advance for our profession would require having a member of every coronary surgical team learn how to safely harvest either the (left) radial artery or a second (right) ITA. ${ }^{16}$ Given the potentially increased complexity of multiple arterial grafting, routine assessment of graft patency in the operating room would provide increased confidence and reassurance of technical success and, when necessary, permit revision of unsatisfactory grafts.

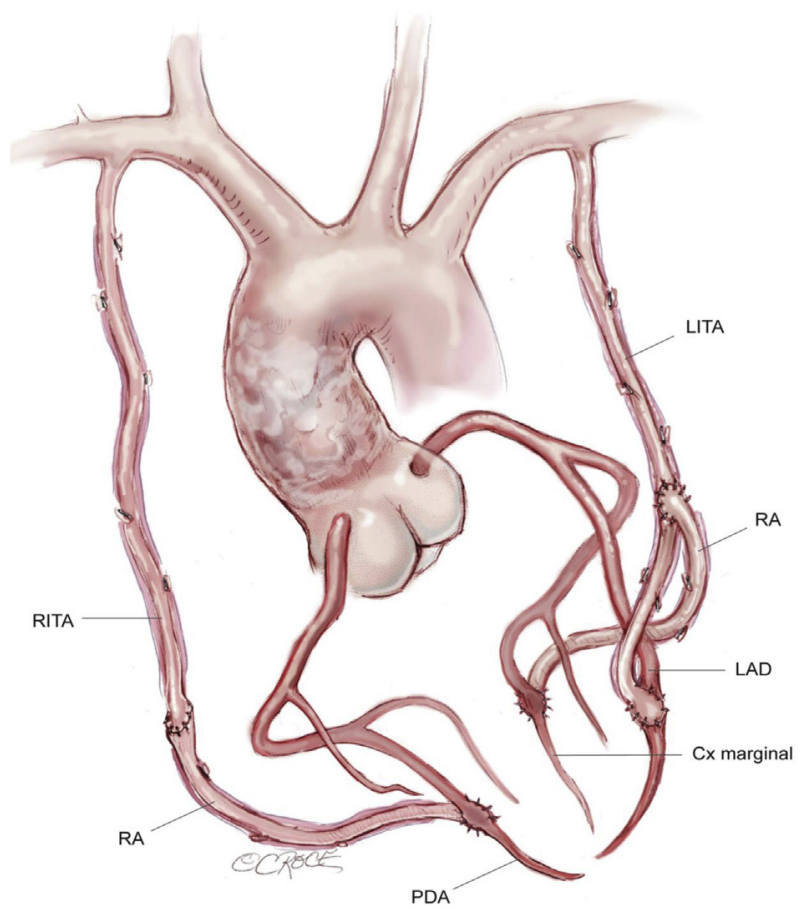

FIGURE 1. Anaortic total arterial grafting using in situ LITA with radial artery $Y$ graft and right internal thoracic artery with radial artery extension. RITA, Right internal thoracic artery; $R A$, radial artery; $P D A$, patent ductus arteriosus; LITA, left internal thoracic artery; $L A D$, left anterior descending; $C x$, circumflex.

The second change that could be easily adopted by all CABG surgeons is the routine use of epiaortic ultrasound scanning to identify atherosclerotic disease of the ascending aorta and guide cannulation/clamping/grafting strategies. Multiple applications of aortic clamps (cross-clamp and partial clamp) has been clearly associated with atheroembolism and adverse cerebral events. This practice should be abandoned in favor of single aortic clamping for on-pump CABG cases (guided by epiaortic ultrasound) and clampless facilitating devices or anaortic techniques in off-pump CABG cases.

Finally, there is an opportunity to improve outcomes in CABG patients without increasing surgical complexity through guideline-directed optimal medical management. To this point, in the FREEDOM trial, among closely monitored patients who underwent $\mathrm{CABG}$, short-term medication compliance was only $88 \%$ for aspirin, $67.9 \%$ for ACE inhibitors, and $83.2 \%$ for beta-blockers. ${ }^{3}$ Guideline-directed medical management has been repeatedly shown to improve survival and event-free survival in CABG patients, yet it is not practiced uniformly.

This appeal for best practices in surgical coronary revascularization begs the questions of how young surgeons should train to perform the state-of-the-art procedure, and how established surgeons should incorporate changes into their routine. In response, The American Association for 


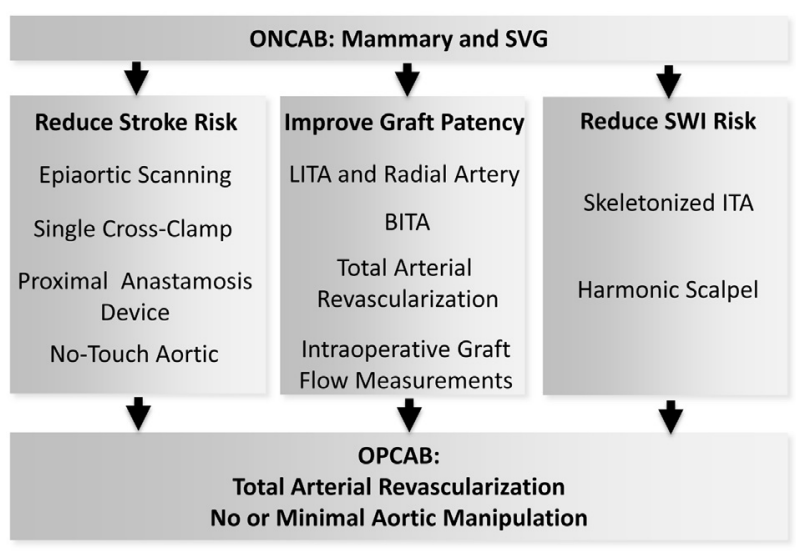

FIGURE 2. Strategies for transition from on-pump CABG to total arterial, minimal, or no aortic manipulation off-pump CABG. ONCAB, On-pump coronary artery bypass graft; $S V G$, saphenous vein graft; LITA, left internal thoracic artery; BITA, bilateral internal thoracic artery; SWI, sternal wound infection; ITA, internal thoracic artery; $O P C A B$, off-pump coronary artery bypass graft.

Thoracic Surgery sponsored the inaugural International Coronary Congress held in New York City on August 21-23, 2015, directed by Dr John Puskas and Mr. David Taggart. This is the first major annual meeting devoted to establishing and disseminating best practices in all types of surgical coronary revascularization. Although more needs to be done, this is a step in the right direction.

\section{References}

1. Loop FD, Spampinato N, Cheanvechai C, Effler DB. The free internal mammary artery bypass graft: use of the IMA in the aorto-to-coronary artery position. Ann Thorac Surg. 1973;15:50-5.

2. ElBardissi AW, Aranki SF, Sheng S, O'Brien SM, Greenberg CC, Gammie JS. Trends in isolated coronary artery bypass grafting: an analysis of the Society of Thoracic Surgeons adult cardiac surgery database. J Thorac Cardiovasc Surg. 2012;143:273-81
3. Farkouh ME, Domanski M, Sleeper LA, Siami FS, Dangas G, Mack M, et al. Strategies for multivessel revascularization in patients with diabetes. $N$ Engl J Med. 2012;367:2375-84

4. Serruys PW, Morice MC, Kappetein AP, Colombo A, Holmes DR, Mack MJ, et al. Percutaneous coronary intervention versus coronary-artery bypass grafting for severe coronary artery disease. $N$ Engl J Med. 2009; 360:961-72.

5. Deb S, Cohen EA, Singh SK, Une D, Laupacis A, Fremes SE, et al. Radial artery and saphenous vein patency more than 5 years after coronary artery bypass surgery: results from RAPS (Radial Artery Patency Study). J Am Coll Cardiol. 2012;60:28-35.

6. Taggart DP, Altman DG, Gray AM, Lees B, Nugara F, Yu LM, et al. Randomized trial to compare bilateral vs. single internal mammary coronary artery bypass grafting: 1-year results of the Arterial Revascularisation Trial (ART). Eur Heart J. 2010;31:2470-81.

7. Lytle BW, Blackstone EH, Loop FD, Houghtaling PL, Arnold JH, Akhrass R, et al. Two internal thoracic artery grafts are better than one. J Thorac Cardiovasc Surg. 1999;117:855-72.

8. Shi WY, Hayward PA, Tatoulis J, Rosalion A, Newcomb AE, Fuller JA, Buxton BF. Are all forms of total arterial revascularization equal? A comparison of single versus bilateral internal thoracic artery grafting strategies. $J$ Thorac Cardiovasc Surg. 2015;150:1526-34.e3

9. Taggart DP, D'Amico R, Altman DG. Effect of arterial revascularisation on survival: a systematic review of studies comparing bilateral and single internal mammary arteries. Lancet. 2001;358:870-5.

10. Weiss AJ, Zhao S, Tian DH, Taggart DP, Yan TD. A meta-analysis comparing bilateral internal mammary artery with left internal mammary artery for coronary artery bypass grafting. Ann Cardiothorac Surg. 2013;2:390-400.

11. Yi G, Shine B, Rehman SM, Altman DG, Taggart DP. Effect of bilateral internal mammary artery grafts on long-term survival: a meta-analysis approach. Circulation. 2014;130:539-45.

12. Kajimoto K, Yamamoto T, Amano A. Coronary artery bypass revascularization using bilateral internal thoracic arteries in diabetic patients: a systematic review and meta-analysis. Ann Thorac Surg. 2015;99:1097-104.

13. Kieser TM, Rose MS, Aluthman U, Narine K. Quicker yet safe: skeletonization of 1640 internal mammary arteries with harmonic technology in 965 patients. Eur J Cardiothorac Surg. 2014;45:e142-50.

14. Rosenberger P, Shernan SK, Löffler M, Shekar PS, Fox JA, Tuli JK, et al. The influence of epiaortic ultrasonography on intraoperative surgical management in 6051 cardiac surgical patients. Ann Thorac Surg. 2008;85: 548-53.

15. Emmert MY, Seifert B, Wilhelm M, Grünenfelder J, Falk V, Salzberg SP. Aortic no-touch technique makes the difference in off-pump coronary artery bypass grafting. J Thorac Cardiovasc Surg. 2011;142:1499-506.

16. Tranbaugh RF, Lucido DJ, Dimitrova KR, Hoffman DM, Geller CM, Dincheva GR, Puskas JD. Multiple arterial bypass grafting should be routine. J Thorac Cardiovasc Surg. 2015;150:1537-45. 